\title{
EFL College Writers' Perspectives on Peer Revisions of De-emphasizing Grammar Correction in Taiwan
}

\author{
Ai-Hwa Chen \\ Dept. of Applied English, Hsiuping University of Science and Technology \\ 11 Gongye Rd., Dali Dist. Taichung City 41280, Taiwan, R.O.C.
}

Tel: 886-4-24961123-4212Ｅ-mail: ahchen@hust.edu.tw

Received: August 14, 2013 Accepted: September 1, 2013 Published: September 1, 2013

doi:10.5296/ijele.v1i3.4209 URL: http://dx.doi.org/10.5296/ijele.v1i3.4209

\begin{abstract}
The purpose of this study is to attempt to realize EFL college students' perspectives on conducting peer revision in the writing class. Students acted as both readers and writers. They were asked to complete feedback questionnaires once they finished editing their peer's work. In their feedback, they pointed out their preferred parts of the essay and describe the reasons for their preference. At the same time, they reflected upon their peer's editing of their own essays. Throughout this process, they were asked to keep in mind the idea writing interesting and engaging essays through the use of narrative, i.e. "telling stories." The findings indicated that some students could not understand their peer's writing because of weak sentence structures. Therefore, they had difficulty elaborating upon and articulating their preferred parts of their peers' writings. However, others highlighted their preference points by relating how they'd encountered similar experiences to those that appeared in their peers' writings. In this, they sensed that they shared the same or similar experiences and stories. By encountering peer revision, almost all of the students involved agreed that the process was very helpful for them to improve their own essays.
\end{abstract}

Keywords: peer revision, narratives, grammar de-emphasis, collaborative learning 


\section{Introduction}

At a workshop held in Taiwan, a speaker was discussing her experience of conducting writing classes with activities for EFL college students. She asked the audience to share their ideas about how to conduct a writing class properly. One person proposed, "How about doing the peer revisions?" The speaker called this into question and claimed that EFL students did not have adequate abilities to conduct this kind of activity in the writing class because their grammar knowledge was insufficient to deal with the task adequately. In particular, it was even harder for those college students who were originally from the vocational high school systems to achieve the hopes for goals. Then, is it true that students with weak grammar knowledge are not adequate to conduct the activity of peer revision and the purpose of peer review has to be solely focused on grammar? This in turn inspired the researcher to explore more comprehensively the effects of peer revision when applied in the EFL writing classes. In this study, 83\% (twenty out of twenty four students) students supposed that the main task for the activity of peer revisions focused on grammar corrections. They believed that good grammar knowledge resulted in better writing performance. However, grammar is always a weakness to most of them. Often in peer writing courses, put aside grammar correction, as they have customarily been implemented, the researcher found that many students usually gave brief and superficial comments, such as 'good' and 'very good', instead of constructive suggestions to their peers. Thus, at least initially, their remarks did not seem to demonstrate what they really learned and how peers could effectively revise one another's compositions through the use of collaborative revision. However, while writing texts were often corrected seriously, the very "grammar only" focus itself may cause the writing composers to grow discouraged and lose confidence in their writing abilities. Especially, for lower level English learners, peer review, in its traditional "grammar fixes" method, may actually result in fostering negative consequences. That is why when students were asked to do the peer revision in this study, one indicated that she was worried to experience a personal attack on her writing texts and another thought that peer revision was like an internecine activity. What if students were asked to point out specific parts of their peers' texts that they found fascinating and give them positive comments about what they found interesting and engaging? Such an approach could perhaps help students to make more sincere efforts to edit the texts collaboratively. Also, students could be asked not only focus on grammar corrections alone but simply to enjoy reading the stories composed by their peers. In this, the narrative - the story that is being told itself, would supersede mere plodding grammar corrections only as the point of the overall exercise.

In the process of conducting the peer revision task, the students were asked to point out the narrative parts they found interesting in their peers' writings and give the reasons for their preferences. What made an essay "a good story" or "an interesting read?" In Taiwan, students have customarily been used to completing their assignments alone and very seldom do the practice sharing their work experiences with one another. Thus, teachers often are the only ones to note students' overall writing progress and the process of individual learning. In general, EFL learners follow instructions given by their teacher and attempt to figure out how to compose a writing text by themselves, without input from others. Thus, their opportunities 
to learn writing skills with one another are rare. This study takes the peer revision activity into consideration. In the process of conducting peer reviews, the writing task can become a mission that is completed collaboratively. It is important to point out that peer revision has been carried out in the ESL and EFL writing classrooms for decades; therefore, a substantial amount of work has been done in this area.

It is worthwhile to explore the appropriateness of peer review for EFL writers, especially the less proficient writers. What perspectives will students have upon peer revision? What will the EFL writers comment on their peers' writing texts? And, will peer revision help students improve their writing skills? This study will assume greater interest in how students can be encouraged to discover the peer editing, introspection, reflection, and narrative regarding their own writing performance.

\section{Literature Review}

The theory of the writing group is based upon the notion of collaborative learning, which draws from Bruffee's social constructional view (1986) that "learning occurs among persons rather than between a person and things" (p. 787). Nystrand and Brandt (1989) indicated that L1 students listen to each other's responses and student improvement in writing is significantly related to the kinds of responses students get from their readers and the ways in which they view their readers.

The need to confirm the affective advantage of peer feedback in ESL was recognized as early as 1976, when peer feedback was just beginning to be accepted by ESL writing teachers. However, Witbeck (1976), an early advocate of peer feedback, warned that the claimed affective advantages of peer feedback in L2 writing were "assumed advantages" without "formal support" (p. 322). It has been assumed that the theoretical rationale for using writing groups in native speaker composition classes is also valid for ESL composition classes. It may appear that the advantages of L1 writing groups would also apply to L2 writers. In addition, many of the arguments supporting the use of L2 writing groups are based on first language research. On closer inspection, however, some differences appear between L1 and L2 populations. L2 students who come from different cultural backgrounds often reflect different attitudes toward working in groups and have different expectations concerning feedback. Another difference between L1 and L2 writing groups is related to language. In the L1 writing class, for example, students can have comprehensive communication in that they share the same language when doing group activities. However, in L2 writing classes, students come from different language backgrounds and cannot operate in their second language as fluently and smoothly while they are engaged in group discussion and giving peer responses. Thus, some second language students do not like to participate in writing groups. In order to give a more systematic and specific argument about the L2 writers' perceptions on writing groups, a series of studies on ESL peer response group interaction would be germane.

Nelson and Murphy's (1992) findings pointed out that students stayed on task by discussing each other's texts. However, the social dimension indicated that this group was not an ideal community of writers helping writers. Although students reported that they benefited from 
the group, they all agreed that they did not feel competent to comment on each other's papers. They would have liked the teacher to be part of the group. Reflecting on Nelson and Murphy's (1992) findings, Zhang's study (1995) concluded that ESL students overwhelmingly prefer teacher feedback. Connor and Asenavage (1994) also recommended, "The teacher should not assume that groups are working smoothly but needs to keep groups on task" (p. 268).

Might similar situations appear in EFL learning environments? Kamimura (2006) conducted a peer feedback study in EFL writing classrooms and found that students at varying levels of English proficiency in the study demonstrated overall positive effects on their composition efforts. By means of employing a web-based platform -- POWER, Chien (2005) also found that EFL writers' concentration on their writing tasks and grammatical accuracy was relatively improved through conducting peer response for revision. Through the use of computer-mediated communication tools, Google Docs (Documents) and Google Talk, Pai (2009) compared synchronous and asynchronous peer review of fourteen EFL college students and indicated that students held a positive attitude toward the incorporation of computer-mediated peer review. By exploring the effect of blog peer review and teacher feedback on the revisions of EFL writers; however, Wu (2006) found that the peer review did not give meaningful and constructive comments, yet complimentary praise or encouragement did. Although this indicates that EFL writers may not improve their writing skills by means of an online blog, but that they can indeed learn the skills of giving positive and encouraging comments to their peers. Similarly, in this study, one goal aimed at examining how students felt a resonance with their peers' writing works (in other words, their "stories"). In order to give appropriate complimentary comments upon their peers' writing works, these student participants were asked to review the writing texts extremely carefully and to locate and indicate areas where the writing "succeeded". In the process of reviewing and providing positive written feedback, hopefully, students indeed improved their own writing performances.

\subsection{De-emphasizing Grammar Correction}

Many researchers have found that a strict adherence to the "grammar corrections only" approach to ESL learning is truly not effective. It's been found, for example, that grammar rules tend to be woven instinctively into language use patterns. It is more important to see what students are trying to say - i.e. their ideas, than to concentrate on how they are saying it. Many studies claimed that grammar correction to second language students is discouraging and even harmful (Sempke, 1984; Kepner, 1991; Truscott, 1996). Cohen (1987) also indicated that focusing on grammatical efforts tends to sidetrack students from issues such as organization and logical development of content. Students regularly do not incorporate such corrections into their work.

Gray (2004) unequivocally felt that veteran teachers know that there is little connection between correction and learning and that those who do not receive grammar corrections have a more positive feeling about writing than those who did, wrote more, and with more complexity, than those who did receive grammar corrections. 
Although there is still debate about these observations, the researcher decided to incorporate a de-emphasis upon grammar correction in this peer review study in order to see if it might indeed play a role in encouraging the participants to write more freely. As a consequence, the participants were instructed initially not to review their counterpart's essays in terms of grammar - whether in terms of errors or successes - but in terms of other criteria. The first criteria was to involve the idea of offering positive feedback, and the second was to respond to the overall interest they experienced when encountering their peer's use of narrative as a writing approach.

In the implementation of peer revision, what progress would such an approach help students to heighten their own writing skills? Also, how would students begin to think differently about the effects of conducting their writing tasks collaboratively? In order to explore the consequences of the issues and ideas presented above, three research questions were proposed, as follows:

\subsection{Research Questions}

- What perspectives will students obtain about conducting the activity of peer revision?

- How will students echo the activity of peer revision to their own writing skills, particularly in terms of emphasizing the importance of narratives?

- How will students perform the role of reviewers in the process of peer review?

\section{Methodology}

This study is methodologically situated within a qualitative research design. For the purpose of realizing what perspectives students would gain through conducting the peer review, the data sources collected included: students' written texts, constant students' feedback, and interviewing. This section includes discussion on the participants, the time frame, the amount and types of written assignments, the use of instrumentation, and feedback questionnaires. The research site was at a technological university located in the center of Taiwan.

\subsection{The Reasons for Conducting Peer Revision Anonymously}

While the teacher/researcher gave the instructions of how to conduct the activity of peer review to the class, she found that many students lacked confidence on their writing and indicated that they were reluctant to provide their names while giving comments on their peers' writing texts. They did not want to offend their peers or risk disapproval because of the comments they gave. Therefore, in order to mitigate students' anxieties and embarrassment, they were asked to read and revise their peers' writing anonymously throughout the activity. In their study, $\mathrm{Lu}$ and Bol (2007) also found that students in anonymous reviews tended to perform better on their writing than those students in a review in which the participant's identities were known to one another.

\subsection{Participants}

Twenty four EFL English major students who were originally from vocational high schools joined in this project. They were all third year students in the college and were all in the same 
class since entering the college. English Writing was a required subject in the English department and it lasted for two consecutive years (four semesters). While the study was being conducted, it was their second year to take the English writing class. The activity of peer review was conducted after class so that participants had more time to read and comment their peers' writing works.

\subsection{Time Frame}

The activity of peer revision was carried out for two semesters. In the first semester, the researcher administered the activity of peer revision occasionally. When the participants were familiar with how to do this activity and became more open-minded and comfortable with sharing their writing texts with one another, peer revision was conducted formally in the following semester.

\subsection{Written Assignments and the Procedure of Conducting the Peer Revision}

The topics were closely related to the ones students usually experienced physically in their life so that it was easier for them to compose. They were encouraged to do their written assignments in a narrative style. Four topics were assigned in the writing class each semester. The length of the texts was one page with three paragraphs of essay writing. Whenever the students completed their first drafts, the teacher would remove the names of the writers from the papers to protect their anonymity before giving the first drafts to the other students to review and make comments on a feedback form. All reviewing tasks were conducted anonymously and students worked on the writing texts composed by different peers each time feedback was made so that they could work with various types of writing styles. After conducting their reviews, the student authors would have their edited drafts returned to them. At this point they were asked to revise their drafts and compose a second draft based on the comments provided by their peers. Subsequent to this, the teacher would collect the second drafts, review them in terms of the initial peer review comments, and then return the second drafts to their composers. Finally, the students were asked to complete third drafts, at which point the writing task was considered to have been completed. In general, it took approximately three weeks to complete each writing assignment.

\subsection{The Use of Instrumentation}

The researcher applied computer program system, automated essay scoring (AES) - My Access, as a supplementary instrument to grade the original and edited writing texts composed by students and their peers. By means of comparing the two different sources of drafts scored by the AES system, the researcher attempted to explore one respect that students perceived on the activity of peer revision. Furthermore, in order to better realize the perspectives students obtained through the use of the activity, they were asked to complete three questionnaires at different stages.

\subsection{Feedback Questionnaires}

There were three kinds of feedback questionnaires employed in the process of conducting the peer revision activity (see appendix A, B, and C). Questionnaire A was completed at the end 
of the first semester. The researcher intended to compare the responses reflected on the questionnaire A with the ones commented on the other questionnaires so as to examine the appropriateness of the peer revision for EFL college writers.

When the project was formally implemented in the second semester, students were asked to complete two other questionnaires, B and $\mathrm{C}$. The students were required to submit them whenever they had completed each writing text. The questionnaire B contained two parts: one was to describe their preferred parts of the edited essay. The second was to give suggestions for the writers and to help them, student editors, gain insight into ways to improve their own writing skills.

Based on the responses of feedback questionnaires, the researcher conducted an interview with participants individually. The students were then asked to provide an overall response concerning their perspectives upon the effects of peer revision on their own writing performance.

\section{Discussion and Findings}

This study aimed at achieving two goals: helping EFL writers learn the skills of expressing positive, genuine comments of their peers' works, particularly through the use of narratives. Also, students could improve their own writing competency through reading and editing the exchanged writing texts mutually. According to the responses given in questionnaire A, more than half of the participants (74\%) liked to share their writings with their peers. Many students were eager to help edit their peers' writing texts as well. Thus, this activity was accepted by most students and conducted successfully.

Four aspects will be discussed in this section so as to realize the appropriateness of peer revision for EFL writers and what concepts the students gained about peer revision and its influence upon their writing tasks.

\subsection{Fostering the Idea of Enjoying Reading Instead of Correcting Grammar Errors}

It mentioned previously that most students initially thought that the purpose for peer review was to help peers correct their grammar. Therefore, before formally performing the task, the researcher asked students to mainly focus on enjoying reading the contents of their peers' writing works and less focused on grammar corrections.

After the students had grown accustomed to conducting the activity of peer revision, in the questionnaires B, they were asked to point out the favorite parts of the essays they had read and to provide reasons for their preferences. Unlike some students focusing upon their peers' incorrect grammar usage, as was the case in the first semester, no students provided such remarks in the following semester. This implies that the students had gradually come to understand the value of offering positive remarks about their peers' writing. This illustrates that, in addition to correcting grammar errors, the focus of peer revision can be shifted to other aspects of composition in the EFL writing class, particularly through teacher guidance. In terms of positive remarks, the reader's preferences could be mainly categorized into three areas: sharing of similar experiences or tastes, compositions that contained good and 
interesting writing, and agreement with the writers' opinions. Nevertheless, one negative remark, "I don't understand", did appear when a student could not quite comprehend what one essay was trying to get at.

This notwithstanding, although most students provided well- intentioned remarks about their peers' writing, some students found few points to comment because they could not understand their peers' English, or the essays they read did not touch their minds. At this point, it seemed that certain students needed to work harder on how to organize their thinking readably into written words, and to simply apply the narrative technique. In many cases, encouraging students to write their stories was interestingly intertwined with the challenge to them to find ways to express comments for their peer's writings.

\subsection{Using Narratives}

Many students indicated that they had similar experiences to those of the writers, so they enjoyed the stories they read. For example, one student stated that she had good memories in her childhood when she lived with her grandparents. Thus, she pointed out her appreciation about her peer's story about living with the grandmother. Nearly all of them were diligent about providing their peers with positive comments about their writing. One said, "I can copy his/her writing style by using 'the first' to start my story." Another reflected, "The sentence, 'Practice makes perfect' is good. I'll use it in my writing next time." One student quoted a sentence from his peer and indicated, "It's a very nice sentence." Many students employed the terms, 'clear,' 'understandable,' 'easy to understand,' 'fluently,' and 'warm,' to express their comments to their peers' writing. In addition, when the writers' opinions corresponded with the readers, student editors would give their appreciation as well. For instance, one student claimed that the writer's expressions truly reflected his own thinking.

Learning how to "tell one's story" is a relative skill, and teachers should keep in mind that some students are innately more adept at it than others. But this doesn't mean that the skill cannot be encouraged, developed, or drawn out. Some students may be better storytellers, even while other, more reticent students may actually have better stories. The point, in this, is that it is a technique that can be highly effective when incorporated into the peer review process. Too often this has been overlooked or marginalized in both EFL classes and peer review projects. Also, the writers should know one purpose for writing is to attempt to catch the readers' attention.

This study was the first time for students to learn the arts of narrative writing as applied to peers' writing tasks. By means of sharing and revising essays with one another, the students obtained the opportunity to read and edit their peers' works mutually. Additionally, their own essays were edited by their peers. According to the comments reflected in their feedback; hopefully, the peer revision activity indeed helped the students to enhance their skills of narrative construction.

The following section will illustrate how students revealed their reactions and thoughts about peer revision in comments that appeared in feedback questionnaires that were provided to them. The study was initiated in the hope that, through the process of reviewing their peers' 
writings and editing comments, the participants would gain a heightened insight into how to more appropriately compose their own essays in the future.

\subsection{Introspections about Revising Peer's Essays}

After editing their peers' compositions, the students were requested to reply to three questions in the questionnaire B in order to present their comments related to the essays they read and concurrently to reflect on how these questions might apply to their own writing efforts. In the following, each question was intended to indicate what students had learned by means of reading and editing essays collaboratively.

Each of these questions is intimately bound up with the notion of writing in a narrative style and observations concerning these connections will be offered.

\section{Q1. What Further Discussion do You Think the Author Needs to Have in the Essay?}

Although students were asked to compose three paragraphs of essay writing using an entire page, they usually provided only half page long responses with two to three paragraphs. Thus, almost all students indicated that the essays composed by their peers were too short and did not express their personal opinions - their stories - completely. They believed that the contents of a legible writing text should be longer so that it would be clearer with detailed description. In addition, some students suggested that the writers could give more examples in their writings so as to convince the readers and draw them into their personal experiences. In regard to the length of the composition, students fairly consistently pointed out that their peers' weaknesses involved essays that were simply too short. (i.e.: They wanted "more" more detail, more intricacy, more self-analysis, more in the way of personal relevance.) However, this was also reflected upon the editors' writings themselves, in that they contained precisely the same frustrating omissions. Thus, while giving suggestions to their peers, the students themselves also tended to sense that their own writing might not be clear enough, or detailed enough, or sufficiently reciprocal. In the process of conducting the writing class, the teacher/researcher constantly encouraged students to give more examples in their essays of life events in order to give clearer pictures to their readers. Therefore, while doing the peer revision, the students increasingly began to suggest that their peers should give more examples and details as well. Writing improvement in this, and a refined sense of what made narratives successful, was clearly taking place.

\section{Q2. What Elements do You Think the Author Needs to Use to Enhance his/her Writing Skills?}

As evidenced in students' expressed opinions, five important components appeared to be needed for reinforcing the participant's writing skills: grammar knowledge, vocabulary usage, the contents of the writing (using stories to draw reader interest), staying on the right track during the narrative, and authentic English speaker's style writing. Despite being urged not to, students continued to emphasize the importance of accurate grammar and structure usage in the writing texts. They suggested that their peers needed to work harder on grammar and structure knowledge, such as tenses, sentence patterns, and preposition usage. In addition to grammar, they also believed that a good essay should not use the same vocabulary words frequently, and instead, apply different words with similar meanings. It is worth mentioning 
in the findings that some students indicated that they could not give any comments concerning the peer revision activity. They found that the essays they read did not present any points related to the topics. Furthermore, some essays strayed from the main subject, thus, the students could only emphasize that the essays should not be off-topic, and offer little else in the way of review. Some students stated that their peers' writing structures were strange and that they could not comprehend the story easily. They found that the 'strange' writing was caused by Chinese expressions appearing in English written formats. In fact, in this study, some students would compose their writing in Chinese first and then translate it into English by themselves or by using a translation machine. Although the teacher kept reminding students not to do this because the machine could not translate the language differences precisely, 'strange' essays still were evidenced occasionally. In general, the less proficient English writers tended to use the translator to do their writing assignment. For the purpose of improving their writing skills without relying on the machine's programming, it would have been better had they spent more time on learning English writing.

In addition to the suggestions on reinforcing the writing skills, two comments appeared by two different students concerning their reflections. One student claimed, "I think he is good enough." Thus, he thought that it was not necessary for his peer to revise his writing texts. Another student uttered, "My English is kind of poor, so I couldn't correct all the errors. However, I worked very hard to revise peer's essay." At this point, it seems that the activity of peer revision may indeed not have been suitable for the less proficient English learners to conduct. (And that the workshop speaker may have been correct in this regard.) However, for those lower achieving writers, they could still enjoy reading their peers' writing texts and give moderate comments. After all, reading and writing are two different skills for EFL learners to explore. And, students with weak grammar knowledge should not be refrained from enjoying reading and appreciating their peers' writing works. It is also one feature the peer revision holds. It is important for writing teachers to conduct an appropriate activity in a mixed-ability EFL writing class. Although less proficient writers may not be able to give constructive suggestions to their peers, they still, nevertheless, can benefit by merely reading their peers' writing works. "I worked very hard to revise peer's essay" is an indication that some had been emboldened at least to try.

\section{Q3. What Have I Learned by Revising Peers' Essay?}

While students gave suggestions to their peers about how to reinforce their writing skills; relatively, they themselves in turn also reflected upon the points that were made about their own writing. As noted earlier, five aspects that were commented upon concerning improving writing involved: enhancing grammar knowledge, using new vocabulary and phrases, content - using stories to better share narratives, staying on the right track while making and sharing narratives, and achieving more fluidity and native speaker style writing. Many students indicated that they had learned many new words and phrases from their peers. In addition, they learned how to use correct tenses, prepositions, clauses, and the past perfect tense. Similar to Lundstrom and Baker's (2009) study, they reflected that the students who focused solely on reviewing peers' writing, made more significant gains in their own writing over the course of the semester. In this study, one student stated that she would copy her peer's writing 
style by applying questions to start her writing. She thought it was a good way to start the writing. Thus, while conducting the activity of peer revision, not only can students experience their peers' writing style, if they like, they may imitate their peers' writing fashions. Likewise, in this study, one student remarked, "Reading peers' essays can learn the differences between theirs and mine." Some students claimed that they truly liked to read their peers' writing and share their stories. Thus, it is not enough for the teacher to evaluate the student's progress in such studies, but to point out to them that, in the process of peer revision, their stories and voices are transmitted to their peers and have a real effect upon them. Instead of being lonely writers, they can be asked to appreciate the fact they have many "listeners" who are interested in their narratives. As mentioned previously, a number of students felt that their peers constructed essays that went off topic. Yet by reading such kinds of compositions, students can come to see that writers should construct their story's prompts carefully and take care in organizing the contents of their writing. Because of the fact that some essays strayed off-topic, some students claimed that they did not learn anything while conducting this activity. However, they applied this fact to their own writings, remarking, "I may make the same mistakes as the peers' did. I should be careful," and, "I may compose an essay that peers cannot understand it as well, so I will organize sentences before I put them down in the future." Again, this clearly indicates that they indeed learned the lessons from the mistakes made by their peers.

Overall, while students pointed out their peers' weaknesses about writing, this often would project into their conceptions of their own writing. Thus, through peer revision, students clearly learned to reflect upon their own writing efforts more deeply and more carefully. This may be one of the most significant processes that this study revealed.

\subsection{Students’Voices about Peer Revision}

More than half students indicated that they would like to help their peers edit their essays and agreed with the activity of exchanging the writing texts with one another to read. However, they had various opinions to it. In the following, it will unveil students' voices on both positive and negative respects towards the activity of peer revision. The voices were based on students' reflection upon the results of the automated essay scoring (AES) system. Before doing the peer revision, students' first draft would be graded by the AES system. After being edited by their peers, their revised writing texts would be graded by AES system again. Based on two grades given by different sources, it would expose students' opinions about the meanings of peer revision conducted among EFL students.

\subsubsection{On Positive/Optimistic Aspects}

Some students thought that their peers could help them revise their essays and optimistically believed that they would make progress gradually on their writing skills. They indicated that their peers would point out the errors which they themselves could not be aware of. Therefore, they trusted their peers. Many students stated that finding other's errors was easier than finding their own. In addition, they appreciated their peers' serious attitudes to edit their essays. Although some students might receive lower scores with the drafts edited by their peers than the original drafts composed by themselves, they still assumed that their peers had 
given them help on essay revision. Instead of complaining to peer's ability, they introspected that the reasons for earning the lower scores were their personal problems. They indicated that they had to work harder on their writing skills.

\subsubsection{On Negative/Pessimistic Aspects}

Contrast to the positive opinions to the scores graded by the computer program, some students argued the effects of peer revision. Students inquired their peers' ability of helping them edit the essays. They questioned that their peers might give them correct or incorrect advice because the scores were the same or even lower than the drafts they did. Under this circumstance, they indicated that they did not know if they had to follow their peers' advice or not. Furthermore, they found that their peers might twist their original meaning and turned their story towards incorrect direction. Thus, they would rather edit the essay on their own than take the texts edited by their peers.

Regard to the activity of peer revision, many arguments have been against it, especially when it is employed in the EFL writing class. It has been a while that the writing teacher is the sole reader to read students' writing texts. As such, students believe that their main task of writing is for the teacher instead of for the public. Therefore, when they are requested to exchange their essays with one another, many unexpected situations may occur. For example, in this study, one female student stated, "If not necessary, I won't correct peer's errors. We seldom practice the English writing, so we should more encourage than correct to one another. Otherwise, when one was corrected all the time, he/she may feel frustrated and doesn't want to try it anymore." Another student indicated, "I'm afraid that my peers may tease my poor writing." Being a writing teacher, he/she has to care about students' inner voice and respect their feelings. Pattison (2008) claimed that it was a big challenge to teach kids how to give meaningful feedback on one another's work. Therefore, the teacher should give students time to comprehend the meaning of this activity and to become familiar with applying it appropriately. After all, in this study, many students indicated that they were fond of conducting this activity and positively agreed that their writing performance would improve gradually.

\subsection{Implications and Suggestions}

Although a de-emphasis on focusing upon grammar corrections was stressed at the beginning of this study, it was evident that many of the students were reluctant to relinquish this approach in their application of peer review. This is most likely attributable to a certain fossilization of both teaching and learning in Taiwan. Students are conditioned to think "grammar corrections" early on in their L2 learning, and it is unfortunately true that it is harder to un-learn something than it is to learn it. Future studies might focus more intensively upon this element of the writing/peer review process, and perhaps even emphasize it exclusively. That said, the element of being fostering the idea of enjoying reading and support when a peer's essay efforts were more successful seemed to meet with greater understanding the students were, in general, more willing to embrace the idea of "joyful readers". In the first semester of the program the students would not give even short verbal comments, such as 'very good' or 'good job', to please their peers. During the second semester, they began to 
give more specific comments to express their feelings. By means of applying the notion of expressing comments in this activity, the writing task became student-centered instead of the traditional teacher-centered learning style. In addition, in order to give appropriate comments, students paid closer attention to reading and editing the writing texts. Therefore, during the formal peer review semester of the project, the students became more responsible and honest to carry out their mission. However, because the majority of the students were used to working on their writing (either Chinese or English) individually, the researcher still needed to give students more intensive guidance on how to conduct the peer revision process effectively during this stage.

Overall, the idea of "telling your story" seemed to have a positive effect upon the participants in this project. Many of their writings were indeed structured around personal events, memories, relatives, family, interesting and actual life experiences. And when such narratives were indeed utilized, the peer reviewers tended to respond positively, citations from the participant's comments frequently affirmed this, ("I can use her style to start my story," "The essay reflected my own thinking," "warm," and so on.) Many expressed an interest in the idea of "talking" to a receptive audience about personal life events, and confirmed that such an approach seemed intriguing, (if somewhat novel.)

In all, because of the continuing de-emphasis upon individualism in Taiwanese culture, the students seemed tentative about expressing their personal stories through writing and peer review, but were certainly attracted to the prospect of trying to do so. Further investigation into this approach in future peer review studies would undoubtedly be fruitful as both a research field and a teaching methodology that could reap genuine rewards.

More than half of the participants positively agreed that the peer review activity could help them improve their writing skills through editing their peers' writing texts and reflecting upon what they had learned as applied to their own writing tasks. This implies that the activity of peer revision can indeed be conducted in the EFL writing class with overall success. However, some students did claim that they could not understand any points on their peers' writing because of the "strange" English usage or off-topic texts. Also, in view of the students' feedback questionnaires, in which many students felt that the main difficulties in their peer's writing mostly had to do with grammar, vocabulary, structure, and Chinese style writing, it would seem that teachers will still need to provide more intensive essential tutorials on de-emphasizing grammar and using narratives (in particular) in order to effectively improve students' writing enjoyment and competency.

\section{Conclusion}

As mentioned previously, at a workshop, one presenter did not agree that the activity of peer revision could be successfully employed in the EFL writing class. She thought that EFL students originally from the vocational school systems had insufficient ability to conduct peer review. Although the effects of peer revision presented by a small sampling of EFL college writers cannot be generalized to the overall situation, this study indicates that EFL writing teachers still can investigate into the usefulness of the activity in their writing classes with some probability of success. After carrying out the activity of formal peer revision for one 
semester, most students agreed that it indeed had positive effects on their writing skills. Also, students became more responsible to help their peers edit their essays and grew more serious about composing their own writings. Instead of criticizing peers' writing texts, they gave more positive comments. And they gained confidence in terms of at least trying to do these tasks. None of these factors should be seen as negative outcomes.

By means of employing the activity of peer revision, the students appeared to alter their learning style from isolated to collaborative learning. In the process of employing the peer revision activity, some students indicated that they found that their peers would compose 'strange' writing texts so that they could not read them successfully. In addition, some essays which seemed to go off-track did appear. This implied that certain students still needed applied tutoring if the peer review process were to be wholly beneficial. Yet in all, the peer review approach continues to have both merit and promise. In applying it, teachers will continue to take key roles.

Further such studies are encouraged, and reports upon the outcomes of their implementation, both positive and negative, should be welcomed.

\section{Acknowledgement}

I would like to thank those students who participated in this study. Without their assistance and cooperation, I could not collect the great variety of precious data which was critical to my study. Also, an immense gratitude to Mr. Ronald Hamilton, a freelance writer, whose work has appeared in many publications, such as O.Henry awards short stories anthologies, Antioch Review, and Confrontation Magazine, for spending his precious time to edit this paper.

\section{References}

Bruffee, K. E. (1986). Social construction, language, and the authority of knowledge: A bibliographic essay. College English, 48, 773-790.

Chien, C. W. (2005). Effects of online peer response on EFL college writing. Unpublished Master's thesis, National Tsing Hua University, Taiwan.

Cohen, A. D. (1987). Student processing of feedback on their compositions. In A. Wenden, \& J. Rubin (Eds.), Learner Strategies in Language Learning (pp. 55-69). New York: Prentice Hall.

Connor, U., \& Asenavage, K. (1994). Peer response groups in ESL writing classes: how much impact on revision? Journal of Second Language Writing, 3, 257-276.

Gray, R. (2004). Grammar correction in ESL/EFL writing classes may not be effective. The Internet TESL Journal, 10(11), November 2004

Kamimura, T. (2006). Effects of peer feedback on EFL student writers at different levels of English proficiency: A Japanese context. TESL Canada Journal, 23(2), 12-39.

Kepner, C. G. (1991). An experiment in the relationship of types of written feedback to the 
development of second language writing skills. Modern Language Journal, 75, 305-313.

Lu, R. \& Bol, L. (2007). A comparison of anonymous versus identifiable e-peer review on college student writing performance and the extent of critical feedback. Journal of Interactive Online Learning, 6(2), 100-115.

Lundstrom, K., \& Baker, W. (2009). To give is better than to receive: The benefits of peer review to the reviewer's own writing. Journal of Second Language Writing, 18(1), 30-43.

Nelson, G., \& Murphy, J. M. (1992). An L2 writing group: task and social dimensions. Journal of Second Language Writing, 1, 171-193.

Nystrand, M., \& Brandt, D. (1989). Response to writing as a context for leaning to write. In C.M. Anson (Ed.), Writing and response: Theory, practice, and research (pp. 209-230). Urbana, IL: National Council of Teachers of English.

Pai, C. W. (2009). A study of comparing synchronous and asynchronous computer-mediated peer review of EFL college students. Unpublished Master's thesis, National Tsing Hua University, Taiwan.

Pattison, D. (2008). Helpful peer feedback. Instructor, 117(4), 66-67.

Sempke, H. D. (1984). Effects of the red pen. Foreign Language Annuals, 17, 195-202.

Truscott, J. (1996). The case against grammar correction in L2 writing classes. Language Learning, 46(2), 327-369. DOI 10.1111/j.1467-1770.1996.tb01238.x.

Witbeck, M. C. (1976). Peer correction procedures for intermediate and advanced composition learners. TESOL Quarterly, 10, 321-326.

$\mathrm{Wu}, \mathrm{W} . \mathrm{S}$. (2006). The effect of blog peer review and teacher feedback on the revisions of EFL writers. Journal of Education and Foreign Language and Literature, 3, 125-139.

Zhang, S. (1995). Reexamining the affective advantage of peer feedback in the ESL writing class. Journal of Second Language Writing, 4, 209-222.

\section{Appendix}

Appendix 1. Feedback Questionnaire A

(1) Do you want your peer to know that you edited his/her essay?

(2) Do you want to know who edited your essay?

(3) Would you like to help your peer edit his/her essay?

(4) Do you think your writing skills can improve when your peer edits your essay?

(5) Do you think that editing your peer's essay can reinforce your own writing skills?

Appendix 2. Feedback Questionnaire B

Q1. What further discussion do you think the author needs to have in the essay? 


\section{Macrothink}

International Journal of English Language Education

ISSN 2325-0887 2013, Vol. 1, No. 3

Q2. What elements do you think the author needs to use to enhance his/her writing skills?

Q3. What have I learned by revising peers' essay?

Appendix 3. Feedback Questionnaire C

(1) Do you think your reviewer edited your essay seriously?

(2) Do you think your reviewer corrected/modified your errors accurately?

(3) Do you think that your efforts to edit your peer's essay were careful and genuine?

(4) Do you agree/ disagree that peer revision is helpful to your personal writing skills?

(5) Do you think it is easier to discover your peer's grammar errors than your own?

\section{Copyright Disclaimer}

Copyright reserved by the author(s).

This article is an open-access article distributed under the terms and conditions of the Creative Commons Attribution license (http://creativecommons.org/licenses/by/3.0/). 